\title{
Antibacterial Effects of Mixtures of Press Oils of Laurel (Laurus nobilis) and Black Seed (Nigella sativa)
}

\author{
Burhan SARIKAYA ${ }^{*}$, Hatice Hüsna ALPEREN¹, Sadık AKGÜN² \\ ${ }^{1}$ Fatih Anatolian High School, Ministry of National Education, Adryaman, Turkey \\ ${ }^{2}$ Department of Medical Microbiology, Faculty of \\ Medicine, Adryaman University, Adryaman, Turkey
}

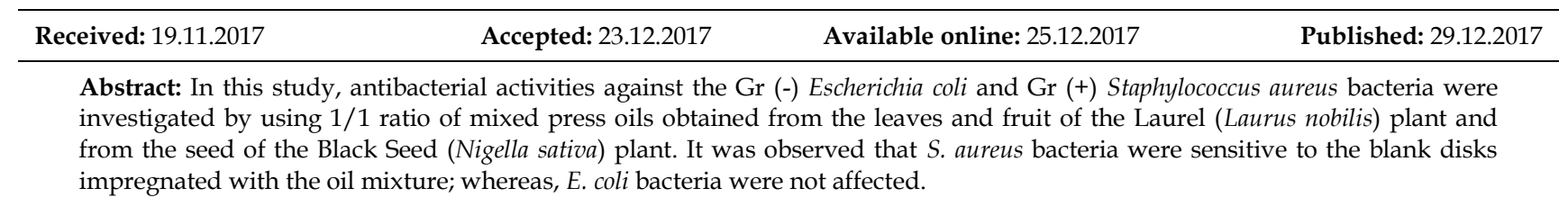

Keywords: Plant, press oil, antibacterial activities, inhibisyon zone

\section{Defne (Laurus nobilis) ve Çörekotu (Nigella sativa) Bitkilerinin Pres Yağ karışımlarının Antibakteriyal Etkisi}

Özet: Bu çalışmada defne (Larus nobilis) bitkisinin yaprakları ve meyvesinden elde edilen pres yă̆ ile çörek otu (Nigella sativa) bitkisinin tohumunun preslenmiş yağlarının 1/1 oranın karışımları kullanılarak, Gr (-) Escherichia coli ve Gr (+) Staphylococcus aureus bakterilerine karşı antibakteriyal aktiviteleri araştıılmıştır. Yağ karışımı emdirilmiş boş disklere karşı S. aureus bakterisinin hassas olduğu, E. coli bakterisinin ise etkilenmediği gözlenmiştir.

Anahtar kelimeler: Bitki, pres yağ, antibakteriyal aktivite, inhibisyon zon

\section{Giriş}

Dış etkilerden kaynaklı travma ve günlük yaşantıda farkında bile olmadığımız birçok olay vücudumuzun birincil savunma bariyeri olan derimiz tarafından bertaraf edilmektedir (Aksoy 2013). Günlük el dezenfeksiyonunda sabunlar, dezenfektan solüsyonlar vs. sıkça kullanılmaktadır. El ve deri temizliğinin hastalıklara yakalanma riskini azalttığı herkes tarafından bilinen bir gerçektir (Nakipoğlu ve Gürler 2004). Dünyada ve ülkemizde tıbbi açıdan önemli bitkiler halk arasında hala kullanılmaktadır (Kalayçığlu ve Öner 1994). Bitkisel yağlar spazm çözücü, irrite edici, antiseptik ve antimikrobiyal özellik göstermektedir ve doğal antimikrobiyal bileşiklerin gıdaların ve insan hastalıklarının kontrolünde de önemlidir (Uçan 2008). Bilim insanları, mikroorganizmaların antibiyotiklere karşı geliştirdikleri direnç sebebiyle bitki türlerinden izole edilen, patojen mikroorganizmalara karşı aktif bileşikleri araştırmaya yönelmişlerdir (Essawit ve Srour 2000). Son yıllarda sentetik kökenli maddelerin yan etkilerinin fazla olması özellikle de antimikrobiyal ve antibakteriyal olarak kullanılan ilaçlara mikroorganizmaların direnç kazanması doğal bitkisel kaynakların ve bu özellikleri taşıyan tıbbi bitkilerin önemini artırmıştır (Nakipoğlu ve Otan 1992). Araştırmacılar, mikroorganizmaların antibiyotiklere karşı geliştirdiği direnç sebebiyle de bitki türlerinden izole edilen, patojen mikroorganizmalara karşı biyolojik olarak aktif bileşiklerinin aktiviteleri birçok araştırmaya konu olmuştur (Grassmann ve Elstner 2000). Bitkilerden elde edilen uçucu yağlar antiseptik ve antibiyotik özellikleri bakteri küf ve mayalara karşı etkili olabilmektedir (Evren ve Tekgüler 2011). Bitkisel uçucu yağların antimikrobiyal özellikleri konusunda artan çalışmalara; Oğuz ve ark. (2008), Evren ve Tekgüler (2011), Haşimi ve ark. (2015) örnek verilebilir. Kızıl ve ark. (2014) yaptıkları çalışmada 7 bitki türünün (Origanum onites, O. vulgare var. hirtum, O. vulgare var. gracile, O. syriacum, Satureja hortensis, Thymbra spicata ve Thymus vulgaris) uçucu yağlarının yüksek antimikrobiyal aktivitelerini, Nychas (1995) ise kekik, adaçayı, biberiye, karanfil, kişniş, sarımsak ve soğandan elde edilen uçucu yağların antimikrobiyal aktivitelerini bildirmiştir. Uçucu yağlarda bulunan fenolik bileşiklerin antimikrobiyal aktiviteye sahip olduğu bilinmektedir. Evren ve Tekgüler (2011) yaptıkları çalışmada defne bitkisinin uçucu yağının Escherichia coli, Pseudomonas pyocyaneus, Yersinia enterocolitica, Aeromonas hydrophila, Enterococcus faecalis, Saccharomyces cerevisiae, Kluyveromyces fragilis bakterilerine karşı hassas olduğunu bildirmiştir.

Defne (Larus nobilis) yapraklarının ağıda çiğnenmesiyle ağız kokularını giderebilir, sindirim salgılarını arttırır (Erden 2005). İştahı açar, hazmı kolaylaştırır, bağırsak kurtlarını dökücü, yapraklarından yapılan gargara diş çürümelerini önleyici, mikrop öldürücü, mukolitik, antiviral, antifungal, antibakteriyel, kas gevşetici ve böcek öldürücü özellikleri bulunur.(Asımgil 1993, Baytop 1999, Schnaubelt 1999, Rose 1999, Wyk ve Wink 2004). Defne bitkisinin meyveleri, vücut parazitlerini (bit, pire, kene vs.) öldürücü, sabunu cilt mantarlarını ve saç dökülmesini yavaşlatıcı, idrar söktürücü, romatizma ağrılarını giderici etkisi vardır (Asımgil 1993, Zeybek ve Zeybek 1994, Baytop 1999). Bitkinin kökünün kabukları kaynatılarak 
içildiğinde böbrek ve mesane kumlarını döker, idrar ve adet söktürür (Karadeniz 2004).

Çörekotu (Nigella sativa) antioksidan aktiviteye sahip olup, iltihabi rahatsızlıklarda tedavi edici olarak kullanılmakta ve bu etkinin uçucu yağın radikal tutucu etkisinden kaynaklandığı bildirilmiştir (Abdel-Wahhab ve Aly 2005). Çörekotu tohumları geleneksel tıpta antioksidan özelliğinden dolayı kullanılmış, yağın ve aktif bileşenlerinin, çevresel veya enfeksiyona bağlı faktörlerce veya anti-kanser ilaçlarca tetiklenen oksidatif stresin aracılık ettiği toksisiteyi azalttığı görülmektedir (Demir 2014). Piras ve ark. (2013) en iyi antimikrobiyal aktiviteyi çörek otunda gözlemlediklerini bildirmişlerdir.

Yapılan birçok çalışmada bitkilerin uçucu yağları kullanılmış bitkilerin meyvesi, yaprağı yahut tohumunun preslenmiş yağları kullanılmamıştır. Bu çalışmada defne (Larus nobilis) bitkisinin yaprakları ve meyvesinden elde edilen pres yağ ile çörek otu (Nigella sativa) bitkisinin tohumunun preslenmiş yağlarının $1 / 1$ oranın karışımlarının sinerjist etki olarak antibakteriyal özellikleri tespit edilmesi amaçlanmıştır.

\section{Materyal ve Metod}

\subsection{Materyal}

Defne bitkisinin meyve ve yapraklarından presleme yöntemiyle elde edilmiş olan $500 \mathrm{ml}$ yağ, Hatay ilinde attar olarak tabir edilen baharatçılardan alınmıştır. Çörek otu-tohumu yağı ise Adıyaman ilindeki attarlardan hazır bir şekilde $500 \mathrm{ml}$ olarak temin edilmiştir. Pres yağlar bire bir oranında karıştırılarak karışım yağı elde edilmiştir. Elde edilen karışım yağın, antibakteriyal aktivitesini ölçmek için kanlı agar, disk düfüzyon testi için boş diskler, pozitif kontrol için $30 \mathrm{mg}$ Vancomicine ve $30 \mathrm{mg}$ Klaritromisin emdirilmiş hazır anibiyogram diskler ("Bioanalyse" marka), Gr (+) Stafilococcus aureus ve Gr (-) Escherichia coli bakterileri, kullanılmıştır.

\subsection{Metot}

Defne yağı ve çörek otu yağıdan $15^{`}$ er $\mathrm{ml}$ alınarak $30 \mathrm{ml}$ yağ karışımı elde edilmiştir. Bu yağ karışımının antibakteriyel özellikleri için $S$. aureus ve $E$. coli bakterilerinden örnekler serum fizyolojikle iki ayrı tüpte sulandirıldıktan sonra her biri farklı kanlı agar besiyerlerine uygun şekilde ekilmiş ve $10 \mathrm{dk}$. oda sıcaklığında beklemeye bırakılmıştır. $\mathrm{Bu}$ bekleme esnasında iki farklı boş disklerin her birine $20 \mu \mathrm{L}$ yağ karışımları mikropipetler yardımıyla emdirilmiştir. Emdirilme işlemi bittikten sonra kanlı agar besiyerlerine yerleştirilmiştir (Şekil 1). Her test farklı zamanlarda 2 tekrar halinde gerçekleştirilmiş, sonuçlar ortalama \pm standart sapma halinde verilmiştir.

Aynı besiyerlerine pozitif kontrol amaçlı $30 \mathrm{mg}$ Vancomicine ve $30 \mathrm{mg}$ Klaritromisin hazır antibiyogram diskleri de yerleştirilerek $37^{\circ} \mathrm{C}$ de 24 saat bekletilmiştir (Şekil 1).
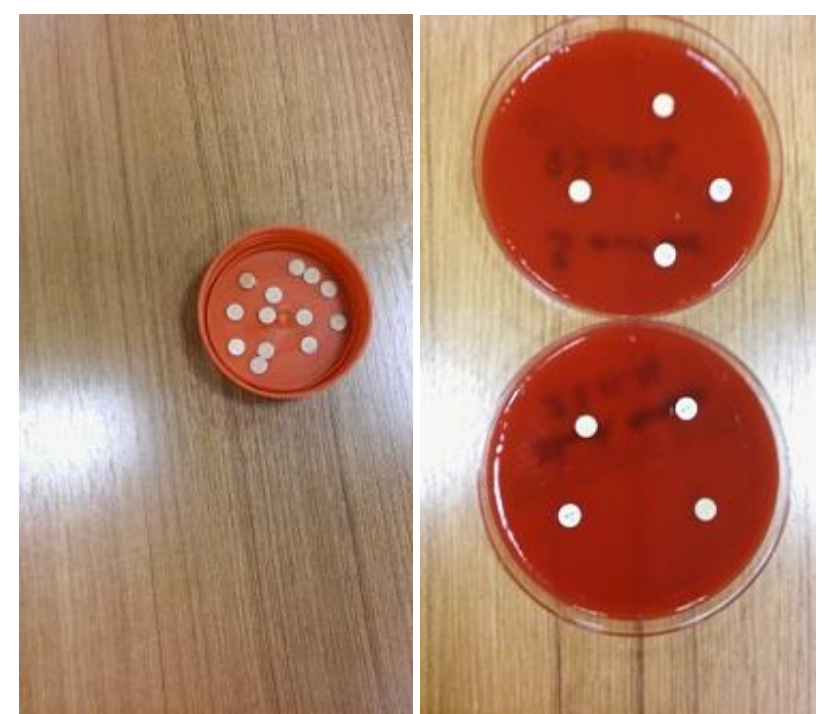

Şekil 1: Yağ karışımı emdirilmiş boş disklerin kanlı agara yerleşimi

\section{Sonuçlar ve Tartışma}

24 saatlik sürenin sonunda besiyerlerinde hassasiyet zonları ölçülmüştür. E. coli ekimi yapılan besiyerinde antibiyotik emdirilmiş hazır diskler ve yă̆ karışımı emdirdiğimiz disklere karşı bir hassasiyet gözlenmemiştir (Şekil 2). S. aureus ekimi yaptığımız besiyerinde ise $30 \mathrm{mg}$ Vancomicine karşı $23 \mathrm{~mm}, 30 \mathrm{mg}$ Klorotromisine karşı $17 \mathrm{~mm}$, yağ karışımına karşı ise 11 mm'lik inhibisyon zonu ölçülmüştür (Şekil 2) (Tablo: 1-2).

Tablo 1: Mikroorganizmaların pozitif kontrolleri

\begin{tabular}{|c|c|}
\hline Test Mikroorganizmaları & İ̀nibisyon zon çapları (mm) (Pozitif kontrol) \\
\hline \multirow{2}{*}{ Stafilococcus aureus $\mathrm{Gr}(+)$} & Vancomicine $30 \mathrm{mg}: 23 \pm 0,4$ Hassas* \\
\hline & Klorotromisin 30mg $17 \pm 0,2$ Hassas* \\
\hline \multirow{2}{*}{ Escherichia coli $\mathrm{Gr}(-)$} & Vancomicine $30 \mathrm{mg}$ : 0 Dirençli* \\
\hline & Klorotromisin 30mg: 0 Dirençli* \\
\hline
\end{tabular}

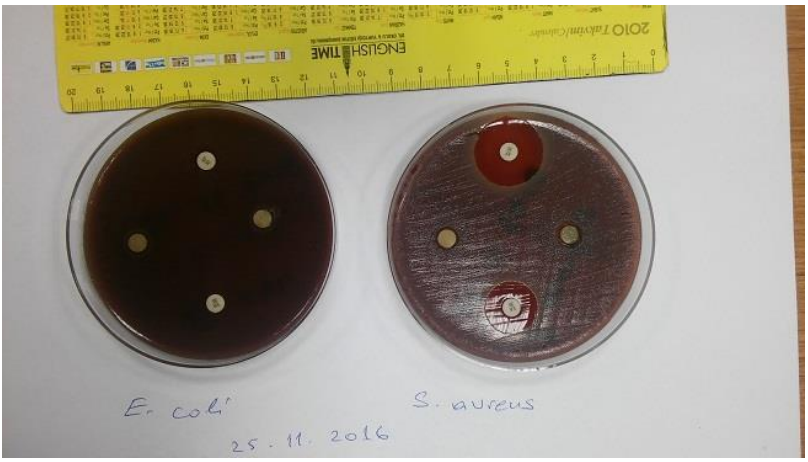

Şekil 2: Kanlı agarda disk etrafındaki inhibisyon zonları

$20 \mu \mathrm{L}$ yağ karışımının oluşturduğu inhibisyon zon çapı bu karışımın düşük antibakteriyel özellikte olduğunu göstermektedir. Disklere daha fazla yağ karışımı emidirilerek zon çapının artırılabileceği öngörülmüştür. Pek çok araştırıcı tarafından uçucu yağların antibakteriyel etkisi kanıtlanmış, sentetik antibakteriyeller yerine kullanılabileceği gösterilmiştir (Oğuz ve ark. 2008). Fakat uçucu yağların elde edilmesi hem zor hem de maliyeti yüksek bir işlem gerektirir ayrıca miktar olarak da az elde edilir. Uçucu yağların 
yerine meyve, yaprak veya tohum pres yağlarının kullanılması daha kolay, ucuz ve miktarı çoktur.

Tablo 2: Mikroorganizmaların yağ karışımı emdirilmiş diklerde zon çapları

\begin{tabular}{ll}
\hline Test Mikroorganizmaları & $\begin{array}{l}\text { İnhibisyon zon çapları }(\mathrm{mm}) \text { Yağ } \\
\text { karı̧ımı(1/1) }\end{array}$ \\
\hline Stafilococcus aureus $\mathrm{Gr}(+)$ & $11 \pm 0,2$ Hassas \\
Escherichia coli $\mathrm{Gr}(-)$ & 0 Dirençli \\
\hline
\end{tabular}

Torunoğlu ve ark. (2006) defne bitkisinin uçucu yağının antimikrobiyal aktivitesini ölçmüş, Oğuz ve ark. (2008) Thymbra spicata var. spicata L, Cyclotrichium stamineum, Teicrium polium L, Salvia russelli, Mentha longifolia var. calliantha bitkilerinin uçucu yağlarının antimikrobiyal etkilerini göstermek için Stafilococcus aures bakterisini kullanmışlar ve disk difüzyon yöntemi de boş disklere uçucu yağlar emdirilmiş ve sırasıyla $25 \mathrm{~mm}, 19$ $\mathrm{mm}, 14 \mathrm{~mm}, 20 \mathrm{~mm}$ ve $15 \mathrm{~mm}$ zon çapı ölçmüşlerdir. Evren ve Tekgüler (2011) Defne bitkisinin uçucu yağı ve gentamicin antibiyotiğiyle birlikte kullanmış ve Stafilococcus aureus bakterisine sinerjit etkisinin olduğunu rapor etmişlerdir.

Haşimi ve ark. (2015) rezene ve ada çayı bitkisinin uçucu yağlarının antimikrobiyal etkisini göstermek için Stafilococcus aureus bakterisini kullanmıs, her iki bitkiden de $10 \mu \mathrm{L}$ ucucu yağ boş disklere emdirerek kullanmış ve rezene bitkisi uçucu yağı aktivitesi için inhibisyon zon çapını $14 \mathrm{~mm}$, ada çayı için ise $16 \mathrm{~mm}$ bulmuşlardır.

$\mathrm{Bu}$ çalışmada kullanılan pres yă̆ karışımının Stafilococcus aureus bakterisine antibakteriyal etkisi disk düfizyon yöntemine göre $11 \mathrm{~mm}$ zon çapı ile ölçülmüş olup önceki uçucu yağlarla yapılan çalışmalara yakın bir değerdedir.

Daha önce yapılan çalışmalar elde etmesi zor ve ekonomik olarak pahalıya mal olan uçucu yă̆ ile yapılmış çalışmalardır. Elde etmesi kolay ve ekonomik olarak maliyeti daha az olan pres yağ ve karışımlarıyla yapılan bu çalışma ilk olma niteliğindedir. Bu çalışmada pers yă̆ karışımlarının da antibakteriyal etki göstermesi uçucu yağların yerine kullanılabileceğini göstermektedir.

\section{Kaynaklar}

Abdel-Wahhab, M. A., Aly, S. E. 2005: Antioxidant property of Nigella sativa (black cumin) and Syzygium aromaticum (clove) in rats during aflatoxicosis. Journal of Applied Toxicolgy, 25 (3): 218-223.

Aksoy, B. 2013: Derinin Doğal Bağışıklık Sistemi. Türkderm, 47: 2-11.

Asımgil, A. 1993: Şifalı Bitkiler. Timaş Yayınları, Türkiye.

Baytop, T. 1999: Türkiye'de Bitkiler ile Tedavi (Geçmişte ve Bugün). İstanbul Üniversitesi Eczacılık Fakültesi Yayınları (İlaveli İkinci Baskı), Türkiye.

Demir, H. N. 2014: Bazı Çörek Otu ve Üzüm Çekirdeği Yağlarının Kalitelerinin Araştırılması. Erciyes Üniversitesi Eczacılık Fakültesi. Bitirme Ödevi.

Erden, Ü. 2005: Akdeniz Defnesi (Laurus nobilis 1.)'nde Mevsimsel Varyabilite ve Optimal Kurutma Yöntemlerinin Araştırılması. Çukurova Üniversitesi Fen Bilimleri Enstitüsü Yüksek Lisans Tezi.

Essawi, T., Srour M. 2000: Screening of some Palestinian medicinal plants for antibacterial activity. Journal of Ethnopharmacology, 70: 343-349.

Evren, M., Tekgüler, B. 2011: Uçucu Yağların Antimikrobiyel Özellikleri. Elektronik Mikrobiyoloji Dergisi, 9 (3): 28-40.
Grassmann, J., Elstner, E. F. 2003: Essential Oils/properties and uses.Encyclopaedia of Food Science, Food Technology and Nutrition (Elsevier Science Ltd), 2177-2184.

Haşimi, N., Kızıl, S., Tolan, V. 2015: Rezene ve Adaçayı Uçucu Yağlarının Antimikrobiyal Aktivite Üzerine Bir Araştırma. Batman Üniversitesi Yaşam Bilimleri Dergisi; 5 (2): 227-235.

Kalaycıoğlu, A., Öner, C. 1994: Bazı Bitki Ekstratlarının Anti Mutajenik Etkilerinin Ames-Salmonella Test Sistemi İle Araştırılması. Turkish Jornual of Botany, 18: 117-122.

Karadeniz, T. 2004: Şifalı Meyveler (Meyvelerle Beslenme ve Tedavi Şekilleri). Burcan Ofset Matbaacılık Sanayi, Türkiye.

Kizil S., Hasimi N., Tolan V. 2014: Biological Activities of Origanum, Satureja, Thymbra and Thymus Species Grown in Turkey. Journal of Essential Oil Bearing Plants, 17 (3): 460-468.

Nakipoğlu, M., Otan, H. 1992: Trbbi Bitkilerin Flavanoitleri. Anadolu Journal of AARI, 4 (1): 70-93.

Nakipoğlu, Y., Gürler, B. 2004: Çeşitli Dezenfektan veAntiseptik Maddelerin Antibakteriyal Etkinliğinin Araştırılması. Ankatem Dergisi. 18 (4): 220-223

Nychasg, J. E. 1995: Natural antimicrobials from plants, In: New methods of food preservation, (Eds:G. W. Gould), London: Blackie Academic Professional.

Oğuz, D., Akın, M., Saraçoğlu, H. T. 2008: Şırnak-Silopi Yöresinse Doğal Olarak Yetişen Labiatae Familyasına Ait Bazı Bitki Uçucu Yağlarının Antibakteriyel Özellikleri. Selçuk Üniversitesi Fen Edebiyat Fakültesi Dergisi, 31: 59-66

Piras, A., Rosa, A., Morongiu, B., Porcedda, S., Falconieri, D., Dessi, M. A., Özçelik, B., Koca, U. 2013: Chemical Composition and in vitro Bioactivity of the Volatile and Fixed Oils of Nigella sativa L. Extracted by Supercritical Carbondioxide Elsevier, 46: 317-323.

Rose, J. 1999: 375 Essential Oil and Hydrosols. P: 48-49. Frog Ltd. Berkeley, California.

Schnaubelt, K. 1999: Medical Aromateraphy. Healing with Essential Oils. P: 213-214. Frog Ltd. Berkeley, California.

Toroğlu, S., Dı̆̆rak, M., Çenet, M. 2006: Baharat olarak tüketilen Laurus nobilis Linn ve Zingiber officinale Roscoe bitki uçucu yağlarının antimikrobiyel aktiviteleri ve antibiyotiklere in-vitro etkilerinin belirlenmesi. Kahramanmaraş Sütçü İmam Üniversitesi, Fen ve Mühendislik Dergisi 9 (1): 20-26.

Uçan, F. 2008: DL-Limonenin mayalar üzerinde antifungal etkisi. Ç. Ü. Fen Bilimleri Enstitüsü Biyoteknoloji A.B.D. Yüksek Lisans Tezi.

Wyk, B. E., Wink, M. 2004: Medicinal Plants of the World. P: 188. Timber Press. Portland, Oregon.

Zeybek, N., Zeybek, U. 1994: Farmasötik Botanik. Kapalı Tohumlu Bitkiler (Angiospermae) Sistematiği ve Önemli Maddeleri. 2. Baskı. Ege Üniversitesi. Eczacılık Fakültesi Yayınları No: 2, Türkiye. 